\title{
GESTALT-TERAPIA: UM MÉTODO DE TRABALHO PARA O PROCESSO SAÚDE-DOENÇA EM ONCOLOGIA
}

\author{
Gestalt-terapy: a method of work for the health-disease process in oncology \\ Gestalt-therapy: un método de trabajo para el proceso de salud- enfermedad en oncología
}

Mariana CoRreia LACERDa Lílian Cherulli de Carvalho Jorge Ponciano Ribeiro

\begin{abstract}
Resumo: A Gestalt-terapia é proposta como um método de trabalho para atendimentos, intervenções, acompanhamentos psicológicos e psicoterapia no tratamento oncológico. Por olhar o ser humano em sua totalidade, essa abordagem proporciona a abertura de consciência aos indivíduos para que não se percebam somente como pessoas adoecidas e entendam as implicações causadas por essa experiência, desenvolvendo ajustamentos criativos e ampliando o contato consigo, com o mundo e com o próprio adoecer. O processo saúde-doença é concebido nesse artigo como um processo complexo, pensa-se sobre a importância da atuação do psicólogo ao longo de todo o caminho para a saúde, como agente que media a relação do sujeito com o adoecimento, partindo dos paradigmas da Psicologia da Saúde, Psicologia Hospitalar e Psico-oncologia.
\end{abstract}

Palavras-chave: Gestalt-terapia; Psicologia da Saúde; Psico-oncologia, Oncologia; Saúde-Doença.

\begin{abstract}
Gestalt-therapy is propose as a method of psychological treatment, interventions, counselling and psychotherapy in cancer treatment. By looking at the human being as a totality, this approach provides the opening of conscience to individuals so that they do not see themselves only like sick persons and understand the implications caused by this experience, developing creative adjustments and expanding contact with themselves, with the world and with their own sickness. The health-disease process is considered in this article as a complex process. It reflects upon the importance of the psychologist in all the way to health, as an agent that mediates the individual relationship with the illness, based on the paradigms of Health Psychology and Oncology Psychology.
\end{abstract}

Keyword: Gestalt-Therapy; Health Psychology; Oncology Psychology; Oncology. Health-Disease.

Resumen: La Gestalt-terapia se propone como un método de trabajo para la atención, intervenciones, acompañamientos psicológicos y psicoterapia en el tratamiento del cáncer. Al observar el ser humano en su totalidad, este enfoque proporciona abertura de conciencia a las personas para que no se consideren sólo como personas enfermas y entiendan las consecuencias causadas por esta experiencia, el desarrollo de ajustes creativos y aumentando el contacto con si mismo, con el mundo y con los enfermos a sí mismo. El proceso de salud-enfermedad está diseñado en este artículo como un proceso complejo, se piensa acerca de la importancia del psicólogo a lo largo de todo el camino a la salud, como un agente que media en la relación del sujeto con la enfermedad, a partir de los paradigmas de Psicología de la Salud y la Psicogía Oncológica.

Palabras Clave: Gestalt-terapia; Psicología de la Salud; Psicogía Oncológica; Oncología; Salud-Enfermedad.

\section{Introdução}

Nas instituições de saúde e também nos modelos terapêuticos comumente aceitos verifica-se que o ser humano adoecido é obrigado a deixar de lado seus sentimentos e aflições para se tornar "paciente", posicionando-se de forma passiva durante o tratamento da doença. Deve-se levar em consideração, contudo, que além de sua individualidade, no curso de sua existência real e produtiva, existe uma diversidade de aspectos inter-determinados que envolvem o processo saúde-doença e que o indivíduo é composto por fatores biofisológicos, psicológicos, espirituais, sociais, culturais e econômicos.

A partir dessas considerações, pensa-se na presença fundamental do psicólogo durante o processo de adoecimento. Esse profissional oferece espaço para que a pessoa adoecida expresse seus sentimentos, fale sobre sua doença, seu sofrimento, posicionando-se de modo mais autônomo e empoderado diante da própria experiência de adoecer e de se tratar. Amplia as oportunidades para que o paciente possa ser mais do que um sujeito acometido por uma determinada patologia como, por exemplo, o câncer, e sim um indivíduo que pode manifestar suas emoções durante e após seu tratamento, a respeito de assuntos direta ou indiretamente relacionados à vivência do adoecimento.

Nesses termos, há que se refletir sobre o fazer profissional do psicólogo inserido nas instituições de cuidado da saúde, considerando sua atuação segundo paradigmas da Psicologia da Saúde, da Psicologia Hospitalar e da Psico-oncologia. Inserimos, então, a Gestalt-terapia como um método de trabalho no processo saúde-doença, analisando a importância do atendimento, do acompanhamento, da intervenção psicológica e do trabalho em psicoterapia em todo o processo de adoecimento-tratamento, durante o tratamento oncológico.

Sabemos que a doença física é acompanhada por manifestações emocionais, sendo a experiência de estar doente vivenciada e representada de forma 
única pela pessoa. A relação entre psique e câncer é evidente e tem sido estudado desde Hipócrates, como cita o oncologista, professor e pesquisador Weber (2012), e ainda hoje se buscam essas articulações. Para o oncologista, o estar com câncer não é um evento traumático: o que é traumático são os pensamentos e emoções associados ao adoecimento, como pensamentos de dor, morte, e debilidade, razão pela qual destacamos a importância do psicólogo no processo de adoecimento oncológico e introdução da Gestalt-terapia como método de trabalho nesse contexto.

Frederick Perls, um dos fundadores da Gestalt-terapia, foi um "profundo conhecedor do ser humano e foi buscar onde pôde os conhecimentos necessários a esta compreensão” (Weber, 2012, p. 114), tendo sido influenciado em seu pensamento pela Psicanálise, pela análise do caráter de Reich e pelas religiões orientais do Taoísmo e Zen-Budismo. A compreensão de mundo e de pessoa da Gestalt-terapia, parte de elementos das teorias do Campo, do Holísmo e da Psicologia da Gestalt, bem como dos pressupostos filosóficos do Humanismo, da Fenomenologia e do Existencialismo.

Para Ginger e Ginger (1995), a Gestalt-terapia enfatiza o aqui-agora, pela tomada de consciência da experiência atual abrindo espaço para a percepção emocional e corporal do cliente. Desenvolve uma perspectiva unificadora do ser humano integrando em todas as dimensões sensoriais, afetivas, intelectuais, sociais e espirituais. Favorece um contato autêntico com os outros e consigo, como uma forma de ajustamento criativo do organismo ao meio. Analisa os processos de bloqueio de contato ou de interrupção no ciclo normal de satisfação das necessidades.

Ribeiro (2011) descreve que essa abordagem além de ser uma forma de psicoterapia é um método de trabalho e é uma teoria da pessoa, ao conceber o indivíduo na sua totalidade, aqui-agora, como um campo organismo-meio, em um movimento processual, sempre à procura de alcançar sua melhor forma.

Adotar a Gestalt-terapia como uma metodologia de trabalho psicoterapêutico envolve estar disponível para a emergência de fenômenos que se desvelam no campo, entre as pessoas que se fazem presentes no momento dos atendimentos. Terapeuta e cliente presenciam e vivenciam tais acontecimentos, conferindo novos olhares, sentidos e significados para cada um deles. Envolve ainda compreender as forças mais ou menos conscientes que movimentam as energias vitais, que influenciam no modo como cada pessoa é-no-mundo e age nele. A abordagem gestáltica, em última instância, visa à ampliação da awareness, da consciência de cada pessoa sobre si e sobre o mundo, em busca de autorregulação e realização.

A decisão de escrever sobre o tema Gestalt-terapia e Oncologia surgiu a partir dos atendimentos realizados por uma das pesquisadoras em uma clínica particular especializada em tratamento oncológico. No dia-a-dia do trabalho, foi observada a diferença significativa que o acompanhamento pela psicóloga provocou nos assistidos nos períodos de antes, durante e após o tratamento oncológico, mais especificamente em quimioterapia, radioterapia e cirurgia. Tal diferença pode ser justificada por meio das observações verbalizadas pelos próprios pacientes durante os atendimentos psicológicos e nas reuniões em equipe multiprofissional.

Os pacientes, de fato, falam sobre o processo de adoecimento para muitas pessoas e profissionais, mas é nos atendimentos psicológicos que eles, enquanto indivíduos, encontram um espaço sem julgamentos para falar e serem compreendido sobre como é estar com câncer, encontrando acolhimento e compreensão sobre seu adoecimento.

O encontro fecundo entre a Gestalt-terapia e a Oncologia se dá justamente pela necessidade de acolher esses indivíduos em seu aqui-e-agora, de atendê-los com base no olhar fenomenológico e humano, de acolher esse ser humano em adoecimento físico e psicológico. Esta é a razão de propormos a Gestalt-terapia como uma metodologia descritiva e compreensiva para os atendimentos psicológicos e psicoterapêuticos relacionados ao processo saúde-doença em oncologia. Por ser uma abordagem dinâmica, detém um conjunto de instrumentos para a ampliação de consciência sobre o adoecimento, com um olhar para a totalidade do ser humano adoecido e sua experiência.

Considerando os atendimentos psicológicos e a psicoterapia realizados no processo saúde-doença, a Gestalt-terapia é um método de trabalho que orienta o acompanhamento psicológico, seja nos atendimentos realizados em momentos críticos do tratamento oncológico, como o processo cirúrgico ou a quimioterapia e em psicoterapia durante e após o tratamento médico-oncológico.

\section{Psicologia da Saúde e Psicologia Hospitalar}

A Psicologia da Saúde surge na década de 1970 como um novo campo do saber, a princípio organizada em dois eixos, segundo Angerami-Camon (2006): o primeiro ligado ao campo da Psicologia Clínica, nos tradicionais consultórios particulares e fora das instituições de cuidado em saúde. O segundo, referente ao trabalho do psicólogo em ambulatórios de saúde - cuja atuação, até recentemente, estava subordinada aos paradigmas da Psiquiatria - e nos hospitais gerais, onde, aos poucos, o psicólogo se inseriu como facilitador do processo de tratamento, a partir da demanda da equipe médica.

Para o autor esse campo de trabalho da Psicologia leva em conta a historicidade do paciente, referindo-se à doença como um desequilíbrio entre o físico e o emocional, que provoca intercorrências na realidade social deste sujeito. Tenta compreender o sofrimento do paciente articulando-o com sua realidade existencial, considerando a dor que sente como única, e utilizando a escuta sobre esta dor para compreender sua real dimensão e como ela pode repercutir na vida desse ser adoecido (Angerami-Camon, 2006).

Percebemos, portanto, que a atuação do psicólogo no campo da saúde está fundamentada, em 
contraste com o modelo biomédico tradicional, em uma tentativa de humanização do processo saúde-doença, com o olhar diferenciado sobre o adoecimento, em um acolhimento ao ser adoecido com tudo aquilo que o envolve.

Como uma proposta que resgata a visão integral do indivíduo e a compreensão da saúde-doença como um fenômeno multicausal e interdependente, Sebastiani e Maia (2005) destacam os movimentos que questionaram o papel exclusivo da Medicina na resolução dos problemas de saúde. Pontuam que estes movimentos surgiram por volta dos anos $50 \mathrm{e}$ mais intensamente a partir dos anos 70, firmando de maneira definitiva a posição de confronto ao paradigma do modelo biomédico vigente durante os últimos 150 anos.

Dentro do modelo biomédico, compreendia-se que a demanda para a saúde emanava da instituição hospitalar e, como consequência, o psicólogo da saúde inicia suas atividades e ações dentro dessa instituição. A inserção do psicólogo no contexto hospitalar proporcionou, ao longo do tempo, um reposicionamento de sua própria função, passando a atuar de forma a não ser mais passivo, mas agente ativo no processo de hospitalização, com intervenções mais sistemáticas junto ao paciente, com atendimentos ao longo de todo o período de internação, preventivos, e não somente quando solicitados pela equipe de saúde em função de demandas emergenciais. Em uma atuação que aos poucos foi se tornando reconhecida também pela própria equipe de saúde, o psicólogo hospitalar passa a ser considerado como um profissional da saúde, integrante da equipe multiprofissional de cuidados.

A Psicologia Hospitalar passa a ocupar seu espaço nos hospitais de forma a proporcionar à pessoa adoecida, como cita Romano (1999), a possibilidade de não ser mais aquele objeto do conhecimento e da ação pela equipe médica, mas um participante de seu processo de cura; considerando-o mais do que um ser humano acometido por uma determinada patologia: um agente de suas condições vitais, como uma pessoa que está trabalhando para conseguir reconstruir sua saúde. Enquanto colaborador no processo de cuidado, o psicólogo hospitalar entende que o processo saúde-doença pode ser avaliado levando em consideração não somente os fatores biológicos (como é proposto pelo modelo biomédico) inerentes à patologia, mas também os fatores sociais e psicológicos do paciente, da família e da própria equipe de saúde.

Angerami-Camon (2003) aponta que o psicólogo hospitalar torna-se responsável por minimizar o sofrimento provocado pela hospitalização, trabalhando com todo o contexto de vida da pessoa, as sequelas e manifestações emocionais do processo saúde-doença. A função do psicólogo é apreender o homem como um todo, como um ser que adoece. Esse ser que está em um contexto hospitalar, no qual o saber médico impera sobre um corpo biológico, e que necessita de uma escuta diferenciada que abranja a história de vida do sujeito e promova um espaço para se compreender a história de sua doença. As pessoas precisam de um espaço para falar de si, de sua doença de sua dor, de seu sofrimento, de suas expectativas, de suas fantasias, de seus medos, de suas angústias; não precisam estar somente na posição paciente, de corpo biológico e sem vida, estático e adoecido somente.

\section{Psico-oncologia e Gestalt-terapia}

Weber (2012), médico oncologista, pontua que na Oncologia o "dogma" de que fatores psicológicos influenciam o processo biológico do câncer ainda não é discutido, sendo tratado como um tabu. O autor analisa que: "Se o câncer ocorresse sem qualquer relação com a pessoa e a personalidade do paciente, isto é, se fosse mesmo um evento puramente biológico, então, o paciente seria só uma vítima, apenas um observador passivo de processos físicos irreversíveis" (pp. 57).

É nesse sentido, que pensamos sobre a importância do acompanhamento psicológico ligado à Oncologia, pois como Weber (2012, pp. 57) destaca a partir de suas observações e evidências: "o paciente pode desempenhar um papel no curso de sua doença". Esta é também a proposta da Psicologia da Saúde e da Gestalt-terapia que posicionam o indivíduo como ator durante todo o processo de adoecimento e não somente como um sujeito passivo de seu tratamento. Para Veit e Carvalho (2008), a Psico-oncologia é constituída pela área do conhecimento da Psicologia da Saúde aplicada aos pacientes com câncer, sua família e os profissionais da saúde. O câncer, por muito tempo na história das doenças, passou a ser símbolo das emoções não expressadas, sendo reservada à pessoa com tal enfermidade a idéia de incapacidade de lidar de forma adequada com as questões emocionais de sua vida (Sontag, citado por Veit \& Carvalho, 2008). A Medicina começou, portanto, a perceber que os aspectos psicossociais estavam envolvidos na incidência, evolução e remissão do câncer.

À medida em que se constituiu a percepção da associação entre o câncer e os fatores psicológicos, comportamentais e sociais, fez-se necessário o desenvolvimento de técnicas da Psicologia da Saúde que melhorassem a qualidade de vida dos pacientes, seus familiares e da própria equipe de saúde, aumentando a participação ativa da pessoa em todo o processo de adoecimento e tratamento (Veit \& Carvalho, 2008).

É nesse campo do cuidado com o indivíduo adoecido que a Gestalt-terapia se insere, articulando seu sistema crítico e seus métodos de trabalho à atuação da Psicologia da Saúde e Psico-oncologia. Como uma maneira de escuta a totalidade desse ser humano adoecido, proporcionando um espaço para compreensão de suas questões emocionais e relacionadas ao adoecimento.

\section{Gestalt-terapia e Oncologia: uma articulação possível para atuação do psicólogo no processo saúde-doença}

Para Ribeiro (2006), a Gestalt-terapia é uma abordagem que resgata o humano em sua relação corpo-pessoa, mente-pessoa, ambiente-pessoa, os três ângulos de uma totalidade fenomenológica- 
-existencial. Sendo muito mais do que uma teoria, é ao mesmo tempo, um procedimento, uma metodologia de trabalho, é uma psicoterapia do encontro e do contato.

Ao adotar a Gestalt-terapia como método de atuação humano-existencial, adotaremos o termo pessoa ou ser humano e não paciente como uma opção de se perceber a totalidade do indivíduo em ação e com todo seu potencial proativo, embora em processo de adoecimento.

Em experiência pessoal nesse campo de atuação, uma inquietação surgiu quanto aos atendimentos psicológicos para as pessoas em processo de adoecimento por câncer, em específico, quando aconteciam nos moldes da Psicologia em contexto hospitalar. O modelo tradicional, já descrito, não tem como foco principal a intervenção psicológica e a observação do fenômeno que emerge no campo no momento do atendimento pelo psicólogo mesmo com seu olhar humano e diferenciado para o processo saúde-doença.

Entendemos, no entanto, que se pode ir mais além da escuta terapêutica e da humanização das instituições de cuidado em saúde, como seria o proposto para o atendimento no modelo tradicional da Psicologia Hospitalar. Pode-se trabalhar com o ser adoecido naquele momento do atendimento, realizando, de fato, uma intervenção psicológica mais aprofundada do que somente uma escuta terapêutica. Uma intervenção de escuta ativa marca a presença do terapeuta e da pessoa adoecida, a partir das demandas apresentadas quanto às expectativas de passar pelo processo de adoecimento, a partir de todas as suas inquietações, mais ou menos fortemente relacionadas às experiências do adoecer, seus medos, culpas, frustrações, ansiedade e angústia.

O psicólogo acompanha a pessoa durante todo processo de saúde-doença, seja em forma de atendimentos pontuais e de aconselhamento, seja em um processo de psicoterapia. Suas intervenções psicológicas ocorrem durante esses atendimentos no exato momento do tratamento (como no decorrer da quimioterapia realizada na clínica), tanto quanto em psicoterapia, atentando-se ao modo como se desenvolvem as relações e o contato entre-pessoas e entre a pessoa adoecida e seu campo vital, incluindo o próprio adoecimento que a acomete.

Uma intervenção psicológica em instituições de cuidado em saúde, à luz da Gestalt-terapia, permite o trabalho no aqui-agora da pessoa em tratamento oncológico. É possível trabalhar com a pessoa a experiência que emerge naquele momento e a deixar falar sobre isso, sentir e vivenciar de fato suas emoções, desenvolvendo com esse indivíduo uma intervenção psicológica e terapêutica, mesmo estando no momento do tratamento quimioterápico. Trabalhar para que, mesmo durante alguns minutos do atendimento a pessoa possa entrar em contato com seu sentimento, pensando concretamente como é estar em um processo de adoecimento, como é estar ali recebendo o tratamento, sentindo dores ou simplesmente se sentindo bem, como uma forma de entrar em contato consigo, com a doença e com seu tratamento.

O gestalt-terapeuta não olha a doença e sim a pessoa adoecida, que é também a proposta fundamental da Psicologia da Saúde, e vai além ao abrir espaço para que o indivíduo entre em contato com o como é estar adoecido, com suas potencialidades preservadas, com suas expectativas de vida e futuro. Este contato ocorre nos atendimentos psicológicos, como uma forma de intervenção psicológica, embora no mesmo momento em que se faz quimioterapia ou outro procedimento curativo.

Nos atendimentos à pessoa em tratamento oncológico proposto pela Gestalt-terapia, sob a perspectiva do fenômeno do adoecimento, tem-se a oportunidade de a pessoa entrar em contato com o seu mundo, seu aqui-agora, de atualizar e ressignificar experiências, sentimentos e perspectivas, tais como se sente, pensa, faz e fala em relação ao fato de estar com câncer. Fazer contato com seu corpo adoecido, por vezes mutilado, ampliando a consciência de forma criativa e saindo do fechamento, muitas vezes proporcionado pelo adoecimento, para pensar nas possibilidades de seguir com qualidade de vida a despeito de um adoecimento físico. Abrindo, portanto, possibilidades de contato com sua realidade atual. Em um primeiro momento, contato com o fato de saber da doença, depois contato com seu corpo em tratamento e, por fim, seu corpo após todo o processo de adoecimento. Esse contato pode ocorrer tanto durante os atendimentos pontuais, no momento em que é realizado o tratamento, quanto em psicoterapia.

Contato é a chave mestra para todo o trabalho em Gestalt-terapia. É pelo contato que as nossas necessidades são satisfeitas, necessidades de ter o corpo saudável novamente. É pelo contato que uma emoção é experienciada, em um movimento à procura de mudança, contato é, portanto, energia que transforma. Entrar em contato com o câncer e toda a emoção que o adoecimento insere e transforma sua vida, como uma forma de pensar em todas as mudanças como, melhoria na alimentação, pratica de exercício físico, dar mais atenção a sua saúde e não ao trabalho somente, são formas de mudança de visão de mundo que podem ser modificadas a partir do contato com o próprio adoecimento. Para Ribeiro (2007):

Contato é saúde. Saúde é contato em ação. Qualquer interrupção do contato implica uma perda na saúde. Contato é processo de auto-regulação organísmica. Doença significa interrupção do contato em um dos quatro campos que compõem o espaço vital da pessoa: geobiológico, psicoemocional, socioambiental e sacrotranscendental. A doença implica a perda da totalidade organísmica (p. 53).

Essa é nossa proposta durante os atendimentos psicológicos, abrir-se espaço para olhar o corpo adoecido e entender o seu significado para cada indivíduo que está no processo de adoecimento. Como uma forma de proporcionar a pessoa adoecida um espaço de saúde, de contato com sua au- 
torregulação, olhando não somente para sua parte adoecida, mas para sua totalidade enquanto ser humano em movimento e em contato com todas as suas partes, enquanto pessoa, profissional, filho(a), esposo(a), mãe, pai, amigo(a), etc.

A partir da ideia de ter a Gestalt-terapia como método para a terapia na Oncologia, podemos pensar sobre como se desenvolvem os atendimentos e intervenções psicológicas para os indivíduos antes e durante o tratamento do câncer.

\section{Acompanhamento psicológico no tratamento oncológico, a partir da descrição fenomenológica em Gestalt-terapia}

Nos atendimentos oferecidos, tão logo se tenha um diagnóstico do câncer e se ocorre a preparação para começar o tratamento, pode-se perceber o quanto a pessoa quer ser acolhida, ouvida. Estar diante de uma pessoa-profissional que a escute sem pré-julgamentos ou olhar piedoso favorece tais realizações. E assim cria-se o ambiente de primeiro atendimento psicológico para esse indivíduo que frequentemente relata estar "sem chão", desolado, devastado pela notícia de que está doente e não por qualquer doença, mas de câncer.

Os primeiros momentos do atendimento com o psicólogo que utiliza a Gestalt-terapia como método são para esclarecimentos, até didático, sobre o que é o câncer do ponto de vista biológico (verificando a explicação oferecida pela equipe médica e o que a compreensão pessoal desse esclarecimento), sobre o que é para nossa cultura estar com câncer e como esse olhar cultural influencia na sua própria vivência de estar com câncer, sobre o que é o adoecimento do ponto de vista psicológico e, por fim e mais importante, como esse indivíduo começa a significar o fato de estar adoecido com o câncer. Parte-se de olhar a totalidade existencial da pessoa como ser humano e de olhar seus fatores biológicos, sociais, psicológicos como partes de um indivíduo adoecido.

Sobre essas dimensões, é interessante expor o que comumente costuma-se ouvir/disseminar sobre o câncer. Infelizmente, para muitas pessoas persiste o sentimento de sentença de morte, de perda da qualidade de vida, de ter que parar tudo em sua vida para tratar uma doença que não tem cura. Para muitas mulheres existe o sentimento de perda de sua beleza (queda de cabelo e retirada do seio, por exemplo) e para os homens a perda de sua masculinidade (nos casos de afetação da próstata ou órgãos sexuais). Como seres humanos não gostamos e não queremos sentir dor e, para muitos, o adoecimento está ligado ao fato de sentir dor. Além disso, em nossa cultura hedonista e com desejos de uma "longevidade pueril" não estamos acostumados a falar sobre a morte; a ideia de que o ser humano é finito parece não agradar, e o diagnóstico, por vezes, instaura o pensamento de morte imediata.

Lembramos ainda que o câncer, por muitos anos, foi tratado como "aquela doença", em muito pelo desconhecimento, causado pela ausência de estudos e tratamentos. Segundo Veit e Carva- lho (2008), o primeiro sucesso no tratamento quimioterápico do câncer foi no início da década de 1950, quando começaram os estudos pioneiros para a associação de quimioterapia, radioterapia e cirurgia, ampliando os casos tratados com sucesso, tanto com a cura quanto com o aumento da sobrevida dos pacientes. Transcorridos cerca de 65 anos, ainda convivemos com as ideias de "perda", mas atualmente discute-se mais sobre o tema - causas, consequências, meios de prevenção - e tem-se mais notícias de pessoas que passaram pelo tratamento oncológico com sucesso, diminuindo a sensação de sofrimento, dor e morte imediata.

Nossa realidade brasileira, entretanto, mostra que existem tratamentos e bons profissionais sempre atualizados em relação ao câncer seguindo padrões e protocolos mundiais para atendimentos e tratamentos. Começamos a perceber, então, que é possível tratar o câncer, existindo pessoas que passaram pelo tratamento e estão bem, possuem qualidade de vida e continuam bonitas, alegres, com suas atividades sociais e pessoais.

Com esse olhar baseado em evidências e na totalidade do campo existencial durante o primeiro atendimento psicológico, percebemos que, abordando os aspectos culturais envolvidos com o câncer, o indivíduo começa a entender os sentimentos que surgiram no momento da notícia de seu adoecimento (recebimento do diagnóstico), como pensar que o seu “chão se abriu”. Pode-se, portanto, já nos primeiros atendimentos com o gestalt-terapeuta, ter um espaço para uma ressignificação da própria doença, um contato com emoções, sentimento e sensações.

Holanda (2014) resgata a postura buberiana e pontua que a Fenomenologia pode ser uma postura, uma atitude que abre possibilidades sobre o modo como o ser humano se apresenta e como revela formas de sua existência. Holanda completa que o psicoterapeuta adota, portanto, uma postura compreensiva, uma escuta ativa, observando e, esperando que o outro, enquanto um fenômeno, emerja para sua consciência.

Assim, intervenções psicológicas, por exemplo, podem ser realizadas no momento em que uma mulher se prepara para a cirurgia de retirada da mama. Este dado se transforma para ela, em seu aqui-agora, em um fenômeno destacado emergindo do campo estabelecido pela relação terapeuta-cliente. A compreensão desse fenômeno (com tudo que a ele se relacione) possibilita e favorece a ampliação de consciência dessa mulher sobre o seu aqui-agora. É uma forma de pensar o que significa essa cirurgia para ela, como é ter que passar por esse processo, como é sua relação com seu corpo adoecido e em processo de tratamento.

O campo relacional e vivencial das pessoas também pode ser compreendido como uma totalidade de fatos que afetam diretamente seu comportamento, sendo constituído por forças interdependentes que acontecem no aqui-agora (Ribeiro, 2006). A forma de analisar e explorar o campo das pessoas em processo de adoecimento envolve um olhar para seu contexto de vida atual, como separa- 
ções, falecimento de amigos ou parente, mudanças, perdas. Pode-se identificar pessoas e situações que se destacam - positivamente ou negativamente - ao influenciar sentimentos e racionalizações do sujeito adoecido. Pode-se explorar o modo como estão organizados a família, o ambiente profissional e social, se houve percepção, por parte da pessoa que está sendo acompanhada, de mudanças significativas nas relações que lhe são importantes.

Observando o campo no qual o indivíduo está, temos um espaço para ouvir os relatos sobre sentimentos relacionados ao querer estar vivo, de não entender o motivo de estar doente e ter que passar pelo difícil tratamento oncológico, além de fazer suas famílias e seus amigos passarem por isso também. Para muitos, surge a percepção de que algo em seu passado pode ter acontecido para que hoje estejam doentes, como se o adoecimento fosse uma expiação de culpas pregressas ou castigos.

Abre-se, então, oportunidade de pensar e olhar para o passado sem culpa, com um olhar de aprendizado, de que agora pode-se fazer diferente mesmo adoecido e em tratamento do câncer. Tem-se um espaço para perceber o corpo humano como uma complexa máquina que precisa de manutenção, cuidado, energia e que, por muitas vezes, é negligenciado. Há, assim, ensejo para a ampliação da consciência e a ressignificação de que seu corpo precisa de cuidados. Tem-se oportunidade de considerar como as pessoas costumam esquecer que a vida pode ser curtida, sem tantas cobranças, tantos horários para cumprir, sem tantas coisas para fazer. Abre-se espaço para lembrar que são seres humanos e que podem parar para cuidar si mesmos, porque, por vezes, se cuida mais do outro do que de si, abrindo-se, portanto, a oportunidade de entrar em contato com suas próprias necessidades, que por muito tempo podem ter sido esquecidas.

$\mathrm{O}$ atendimento psicológico se desenvolve por meio da análise do que fazer agora que a doença está presente e precisa ser tratada. O tratamento é um momento oportuno para promover mudanças de olhares e concepções a respeito de si e das necessidades normalmente identificadas como prementes. Nessa perspectiva de acolhimento e de atendimento psicológico, baseado no aqui-agora, buscam-se a focalização de figuras por vezes difusas, a tomada de consciência e a ampliação de awareness, por meio de um espaço de escuta e de reflexão pessoal. Esse momento é propício a uma abordagem, pedagógica, de orientações claras e objetivas sobre os caminhos a serem percorridos em procedimentos médicos, medicamentosos e clínicos, à construção de espaços para tirar dúvidas práticas sobre como será, por exemplo, o primeiro dia de quimioterapia. Algumas estratégias são interessantes e se mostraram eficazes, como conhecer o local e os profissionais que estarão presentes durante o tratamento quimioterápico, mostrar como serão os procedimentos, falar que se pode dormir, comer, ler, assistir televisão, conversar e rir, enquanto recebe a quimioterapia.

Para além do "falar sobre", a visita in loco pode colaborar para uma ressignificação do processo existencial, para a elaboração de novos significados a partir da desmistificação dos ambientes e procedimentos. Pode-se pensar e trabalhar sobre cirurgia, internações, medicações, alimentação, ou seja, abrir um espaço para entrar em contato com o campo no qual ocorrerá o tratamento. Técnicas que se operam por meio da fantasia, que permitam abordar os medos e as idealizações que as pessoas carregam, que permitam abordar incongruências e paradoxos entre a experiência real e a imaginada tornam-se ferramentas úteis para o trabalho terapêutico.

Ao olharmos o fenômeno adoecimento e as perspectivas envolvidas no campo do indivíduo, temos a oportunidade de perceber manifestações de mais esperança, pois a pessoa começa a entender que tratar um câncer não precisa ser vivido como um pesadelo, com um "bicho de sete cabeças" ou como a "pior coisa do mundo". Analisar, que quem sabe, a vida, Deus, um ser superior ou o mundo estão lhe dando a oportunidade de mudar, de aprender, de viver. Percebemos que o indivíduo começa a pensar mais em si mesmo ou em como é bom cuidar de si, se permitindo dizer sim para suas necessidades.

O atendimento e as intervenções psicológicas a partir de propostas da Gestalt-terapia abrem um espaço para reflexão da pessoa sobre o processo de adoecimento, criando a oportunidade para que se pense sobre seu adoecimento e até mesmo sobre questões práticas que surgem com o tratamento, como cortar ou não todo o cabelo antes da primeira quimioterapia, querer ou não contar que está em tratamento do câncer, o que quer fazer durante o período de tratamento e muitas outras partes que necessitam ser enfrentadas pela pessoa.

Pode-se abordar também a experiência vivida no momento exato do tratamento quimioterápico, em um atendimento pontual, valorizando mais uma vez o aqui-e-agora emocional vivido pela pessoa. Algumas questões podem ser salientadas e focalizadas: como é estar sentado naquela cadeira recebendo a medicação; como é estar enjoado e cansado, com tanta medicação e rotina de exames; como é difícil não poder comer tudo o que gostaria; como é saber que dali a dois ou três dias estará passando muito mal pelos efeitos adversos; como é ruim ou bom estar longe do trabalho ou fora da rotina habitual, etc.

Por meio do método gestáltico que prioriza a realidade vivida, descreve a realidade assim como ela se apresenta, permite à pessoa descobrir o sentido de sua experiência, conduz a uma intersubjetividade criativa, dá um rosto à situação real da pessoa. Abrem-se, enfim, oportunidades para que a pessoa entre em contato com todos esses elementos - nem sempre de fácil assimilação e aceitação afetiva -, reconhecendo e trabalhando os bloqueios que impedem melhores processos de ajustamento e autorrealização.

O formato do atendimento do gestalt-terapeuta, durante o tratamento oncológico, leva a pessoa a considerar sempre que apenas uma parte sua está adoecida e não sua totalidade. Dá sentido ao que acontece no seu campo enquanto se cumpre o tratamento, colabora para a significação mais positiva 
e egossintônica de fenômenos e eventos proporcionados como efeitos das próprias terapêuticas, por exemplo, a retirada de uma mama, reflete sobre as expectativas quanto ao impacto dessa realidade na autoestima e em um relacionamento afetivo, as limitações advindas da administração de medicamentos fortes, enquanto em tratamento quimioterápico, entre tantos outros. Tudo isso é parte do seu aqui-e-agora e não forma a sua totalidade enquanto ser humano o reconhecimento dessa condição favorece o ajustamento criativo, a partir de partes saudáveis, buscando manter autonomias e desenvolvendo potencialidades enquanto ser humano vivente, e não somente um ser humano adoecido.

Muitas emoções e novas gestalten surgem nos momentos de atendimento mais pontuais, por isso entendemos ser igualmente importante que se realize o processo de psicoterapia, além dos atendimentos psicológicos durante todo o processo de adoecimento-tratamento oncológico.

\section{Psicoterapia com o método da Gestalt-terapia durante e após o tratamento oncológico}

A importância de se estar em processo psicoterápico, enquanto em tratamento oncológico e até mesmo após, relaciona-se ao fato de que em psicoterapia percebe-se qual é, para a pessoa, conceito de saúde-doença dominante e como é, para ela, a existência do câncer em sua vida, no sentido de ampliação de consciência pelo fenômeno do adoecimento e suas questões relacionadas. Pensa-se também sobre se, e como, essas questões estão relacionadas com sua vida atual e com os acontecimentos de seu passado e perspectiva de futuro.

$\mathrm{Na}$ psicoterapia com indivíduos em tratamento oncológico, quase sempre, ocorre um processo de mudança, por meio do qual a pessoa busca uma ressignificação de suas coisas e da sua própria existência. Busca-se, ainda, é uma ressignificação do próprio ser adoecido, em um processo de mudança contínua de sua existência antes do adoecimento e no seu aqui-agora. $\mathrm{O}$ indivíduo percebe que não pode continuar o mesmo que era antes do adoecimento, pois a mudança é necessária para não passar pelo adoecimento novamente.

Observa-se que uma das primeiras mudanças percebidas é a do olhar para o mundo, com percepções de valores perdidos e novos valores aprendidos, envolvendo coisas simples como cuidar de si mesmo, de seu corpo, de sua alma, valorizando as coisas simples da vida como um passeio no parque ou contemplações da natureza, mudança do ritmo de vida, de trabalho, uma desaceleração necessária e fundamental para sua saúde. Pensando na importância dessas mudanças necessárias, Ribeiro (2007) afirma:

A mudança é decorrência da consciência emocionada, a qual é fruto da intra e interação dos três sistemas, cognitivo, sensório e motor, da pessoa com o meio ambiente. Estes sistemas podem se combinar das mais diferentes maneiras, formando diferentes tipos de comportamento e traços de personalidade. $\mathrm{O}$ self, enquanto central energética holística do desenvolvimento humano, cria condições de mudanças pelo qual abandono de fatores negativos e pelo investimento nos fatores positivos que permitem a evolução e, consequentemente, a mudança da pessoa humana (p. 36).

Weber (2012), médico oncologista, relata suas observações sobre seus pacientes durante anos de acompanhamento do tratamento do câncer e percebe algo em comum entre eles como sentimento de solidão, culpa e autocondenação, questões estas que podem ser trabalhadas com o foco na mudança em psicoterapia.

Faz-se necessário, portanto, uma ampliação de consciência sobre sentimentos "guardados", os não ditos, sobre gestaltens inacabadas, pois o corpo sente o que nós sentimos em nosso coração, alma e mente. Se não colocarmos para fora, o corpo acumula, adoece, fica em uma eterna digestão. Muitos indivíduos relatam desconfortos na garganta, estômago, barriga, como um bolo não dissolvido. Percebe-se que pode ser alguma forma do corpo colocar para fora e de qualquer maneira seus lixos emocionais, como doença cardíaca, câncer, doenças gastrointestinais.

Em psicoterapia, para indivíduos em processo de adoecimento oncológico, trabalhamos o quanto as pessoas se sentiam abandonadas ou sobrecarregadas, como uma forma de pensar sobre seus medos, ansiedades, raivas, culpas e o quanto essas questões influenciam o seu aqui-agora. Percebemos que a pessoa busca a psicoterapia não por estar adoecido pelo câncer, mas sim por uma busca do autoconhecimento para conseguir lidar com questões que o levaram ao adoecimento e como influenciaram seu passado e influenciam no seu presente, em uma continuidade do processo de mudança e autorregulação necessários para a construção do processo de saúde.

Para Ribeiro (2007) o processo psicoterapêutico expõe o modo como o indivíduo faz contato com o mundo e com isso o terapeuta faz contato com seu cliente, permitindo, portanto, entrar na intimidade desse outro para cuidar de suas feridas, em uma forma de "cumplicidade com a totalidade do ser e do existir do outro” (pp. 26). Segundo Vianna (2009), uma psicoterapia gestáltica "mostra-se como uma abordagem plena de recursos estruturados, com métodos e técnicas eficazes em psicoterapia” (pp. 163). A autora ainda completa que é uma abordagem psicoterapêutica flexível e ampla nos recursos necessários para a mobilização de conteúdos que geram sofrimentos e para auxilio no desenvolvimento do potencial humano, buscando a autorrealização.

A Gestalt-terapia atua com o foco em localizar as Gestalten cristalizadas, provocar sua movimentação, promover a conscientização deste sistema que está paralisado e do modo de lidar com ele exercido pela pessoa, e com foco em conduzir a uma ressignificação dos vividos. Esta estratégia baseia-se na crença de que, uma vez revivido o que está retido 
sem solução e, tendo sido formado um novo significado pela pessoa, acontecem as mudanças que permitem o conteúdo ser assimilado adequadamente, não havendo mais a necessidade de empregar a energia que mantinha o sistema embotado (Vianna, 2009, pp. 168-169).

Concordamos com Ginger e Ginger (1995) quando afirma que a terapia é um processo de mudança da awareness (consciência) e do comportamento, sendo essa mudança é necessária para manutenção da saúde física e mental. Pensamos ser importante fazer psicoterapia antes, durante e após o processo de adoecimento pelo câncer, pela abertura, ampliação de consciência e as mudanças que ocorrem durante o processo psicoterápico.

Com o processo psicoterapêutico ao longo do tratamento oncológico observa-se uma melhora na qualidade de vida, pode ser a oportunidade da pessoa atendida estar consciente de sua condição física e psicológica, como uma forma de vivência verdadeira do processo de adoecimento. E o acompanhamento após o termino do tratamento fica claro como as pessoas melhoram sua visão de mundo, entrando em contato com sua vida, se posicionando melhor em relação as suas escolhas pessoais, em um processo de escolha de si colocar em primeiro lugar ao invés do trabalho ou sua família, ou cuidar melhor de sua saúde, escolhendo uma vivência com opções mais saudáveis e menos prejudiciais a sua saúde, por exemplo.

\section{Considerações Finais}

Utilizar a Gestalt-terapia como método de trabalho dentro do processo de tratamento oncológico é abrir espaço para se pensar nossa existência, como forma de ampliar a consciência do indivíduo para ir mais além de ser um doente ou um paciente com câncer, e resgatar o humano, o vivo, o todo e não somente a parte adoecida. É pensar em um espaço de ampliação de oportunidades, de apropriar-se do seu corpo, e em um ajustamento criativo passar do processo de doença ao processo de saúde, aumentando a fluidez, como uma forma de experimentação. É perceber o que, de fato, se é, enquanto ser no mundo, para ir muito além de um corpo adoecido, e ir além da experiência de se auto-conhecer para ter uma qualidade de vida mesmo no processo de adoecimento. É retirar introjetos tóxicos para transformá-los em mecanismos saudáveis de elaboração do vivido, em um processo de mudança constante a partir da ampliação de consciência da nossa totalidade enquanto seres humanos.

Durante o tratamento oncológico, o indivíduo se vê obrigado a entrar em contato com seu corpo de uma maneira diferenciada daquela de quando descobriu o adoecimento físico. Agora, o organismo necessita de outros cuidados, reage de forma diferente, algumas vezes encontra-se anatomicamente ou funcionalmente modificado. Há que se restabelecerem significados para o corpo e novas relações entre self-corpo e pessoa-mundo, dadas por meio desse mesmo corpo que existe e faz contato com os meios interno e externo.
Proporcionar um espaço para ressiginificar o adoecimento, melhorar a qualidade de vida, proporcionar uma abertura de consciência com ampliação das possibilidades e escolhas diante da mudança de visão de mundo proporcionada pelo processo saúde-doença, entrar em contato com o que pode ser modificado na vivência com o outro, melhora na autoimagem e auto-conceito são alguns dos pontos importantes que fazem o uso da Gestalt-terapia como método de trabalho na oncologia, brilhar aos nossos olhos, por percebermos como podemos ser instrumentos de melhora para a saúde e mudança para essas pessoas.

\section{Referências}

Angerami-Camon, V. A (2003). O psicólogo no hospital. Em V. A. Angerami-Camon (Org.), Psicologia hospitalar: teoria e prática (pp. 15-28). São Paulo, SP: Pioneira Thomson Learing, $6^{\circ}$ ed.

Angerami-Camon, V. A. (2006). O ressignificado da prática clínica e suas implicações na realidade da saúde. Em V. A. Angerami-Camon (Org.), Psicologia da saúde: um novo significado para a prática clínica (pp. 7-22). São Paulo, SP: Pioneira Thomson Learing.

Ginger, S. \& Ginger, A. (1995). Gestalt: uma terapia do contato. São Paulo, SP: Summus.

Holanda, A. F. (2014). Fenomenologia e Humanismo. Reflexões necessárias. Curitiba, PR: Juruá.

Ribeiro, J. P. (2006). Vade-mécum da Gestalt-terapia. São Paulo, SP: Summus.

Ribeiro, J. P. (2007). O ciclo do contato: temas básicos na abordagem gestáltica. São Paulo, SP: Summus.

Ribeiro, J. P. (2011). Conceito de mundo e de pessoa em Gestalt-terapia: revisitando o caminho. São Paulo, SP: Summus.

Romano, B. W. (1999). Princípios para a prática da psicologia clínica em hospitais. São Paulo, SP: Casa do Psicólogo.

Sebastiani, R. W. \& Maia, E. M. C. (2005). Contribuições da psicologia da saúde-hospitalar na atenção ao paciente cirúrgico. São Paulo, SP: Act. Cirúrgica Brasileira.

Veit, M. T. \& Carvalho, V. A (2008). Psico-oncologia: definições e área de atuação. Em V. A. Carvalho; M. H. P. Franco; M. J. Kovács; R. P. Liberato; R. C. Macieira; M. T. Veit; M. J. B. Gomes \& L. H. C. Barros (Orgs.). Temas em psico-oncologia (pp 15-19). São Paulo, SP: Summus.

Vianna, K. S. (2009). Gestalt-terapia: uma escolha em psicoterapia. Histórico, fundamentos e conceitos. Brasília, DF: Kátia S. Vianna (publicação própria).

Weber, W. (2012). Esperança contra o câncer: a mente ajuda o corpo. São Paulo, SP: Editora Europa. 
Mariana Correia Lacerda. Mariana Correia Lacerda graduada em Psicologia pelo Centro Universitário UniCeub, especialista em Gestalt-Terapia pelo Instituto de Gestalt-Terapia de Brasília. Atualmente é Psicóloga Clínica da Fundação Universidade de Brasília. Email: marianalacer@gmail.com

Lilian Cherulli de Carvalho possui Graduação e Mestrado em Psicologia pela Universidade de Brasília. Foi Analista de Políticas Sociais do Ministério de Saúde (SAS/ Coordenação Geral de Saúde de Adolescentes e Jovens). Atualmente é Docente do Instituto de Gestalt-Terapia de Brasília e Analista Judiciária na Seção Psicossocial da Vara de Execuções Penais do TJDFT.

Jorge Ponciano Ribeiro é Graduado em Filosofia e Teologia pelo Seminário Provincial de Diamantina, Mestrado e Doutorado em Psicologia pela Ponteficia Università Salesiana. É Professor Titular da Universidade de Brasília.

Recebido em 30.11.2016

Primeira Decisão Editorial em 03.04.2017

Aceito em 14.04.2018 